$\sqrt{2}$ CHOICE

\title{
Epidemiology and aetiology of paediatric malpractice claims in France
}

\author{
A Najaf-Zadeh, ${ }^{1,2}$ F Dubos, ${ }^{1-3}$ | Pruvost, ${ }^{1,2}$ C Bons-Letouzey, ${ }^{4}$ R Amalberti, ${ }^{4}$ A Martinot ${ }^{1-3}$
}

${ }^{1}$ Univ Lille Nord de France, UDSL, Lille, France

2 Paediatric Emergency and Infectious Diseases Unit, CHU

Lille, Lille, France

${ }^{3}$ EA2694, Public Health, Epidemiology and Quality of Care, Lille, France

${ }^{4}$ Sou Médical-Groupe MACSF, Courbevoie, France

\section{Correspondence to}

Professor A Martinot

Département de Pédiatrie,

Hôpital Jeanne de Flandre,

Av E Avinée, 59037 Lille

cedex, France;

alain.martinot@chru-lille.fr

Accepted 23 June 2010

Published Online First

26 July 2010

\section{ABSTRACT}

Objective To examine paediatric malpractice claims and identify common characteristics likely to result in malpractice in children in France.

Design and materials First, the authors did a retrospective and descriptive analysis of all paediatric malpractice claims involving children aged 1 month to 18 years, in which the defendant was coded as paediatrician or general practitioner, reported to the Sou Médical-groupe MASCF insurance company during a 5-year period (2003-2007). Then, a comparison of these results with those from the USA was performed.

Results The average annual incidence of malpractice claims was $0.8 / 100$ paediatricians. 228 malpractice claims were studied and were more frequent (41\%) with more severe outcomes in children younger than 2 years of age (52\% deaths or major injuries). Meningitis $(n=14)$ and dehydration $(n=13)$ were the leading causes of claims, with highest mortalities (93\% and 92\%, respectively). The most common alleged misadventures were diagnosis-related error (47\%), and medication error $(13 \%)$. Malignancy was the most common medical condition incorrectly diagnosed (14\%).

Conclusions Paediatric malpractice claims are less frequent in France than in the USA, but they share many similarities with those in the USA. These data would enhance the knowledge of high-risk areas in paediatric care that could be targeted to reduce the risk of medical malpractices and to improve patient safety.

Patient safety is a major public health problem and medical errors continue to capture the attention of the medical profession, policymakers and the public. ${ }^{1}$ In the UK, studies have shown that adverse events resulting in harm to patients occur in approximately $10 \%$ of admissions. ${ }^{2}$ Adverse events due to medical errors are estimated to cause between 44000 and 98000 deaths every year in the USA and result in a total national cost of \$17-29 billion annually. ${ }^{3}$ These rates are higher than death rates from motor vehicle accidents and place adverse medical events as the eighth most common cause of death in the USA. ${ }^{3}$ In France, the 5 -year-programming public health law of 2003 pointed out the need for analysing iatrogenic injuries, which included medical errors. ${ }^{4}$ Implementing an adverse event surveillance system was considered to be a performance criterion for the healthcare system. ${ }^{4}$ Patient safety issues and medical errors involving children have not been studied as thoroughly as in other patient populations. In a previous systematic review of the literature concerning medical errors with legal consequences in paediatrics, we found only six articles published before July 2007, all based on US data. ${ }^{5}$

\section{What is already known on this topic}

Malpractice claim files are valuable sources to study medical errors. There are just a few studies analysing paediatric malpractice claims, and all published data are North American.

\section{What this study adds}

This study is the first toward providing a description of paediatric malpractice claims in a European country. Paediatric malpractice claims are less frequent in France than in the USA, but they share many similarities with those in the USA.

As the medical malpractice system in France differs from that in the USA, our goal was to analyse the paediatric malpractice claims in France, and to compare them with those from the USA, in order to improve understanding of medical errors in paediatrics and to help in identifying priority areas for interventions that could increase the safety of paediatric care.

\section{MATERIALS AND METHODS \\ Study design}

We conducted a retrospective, descriptive analysis of a nationwide database of paediatric malpractice claims, in which patients alleged an error. Permission from the Sou Médical-Groupe MACSF was obtained to work on their database. All claims involving children less than 18 years of age, in which the defendant was coded as paediatrician (general or subspecialist) or general practitioner (GP) reporting to the Sou Médical-Groupe MACSF from 1 January 2003 to 30 December 2007 were extracted. Claims involving other specialties (anaesthesia, surgery, etc) and the neonatal period were excluded; the claims related to other specialties were most often associated with a specific operation or act, and neonatal cases were most often related to delivery.

While the US medical malpractice system is based on tort law, the French medical malpractice system incorporates elements of fault and no-fault in which injured patients bring claims before their region's government-appointed review board which is responsible for determining whether a fault or no-fault has occurred. The 
indemnification process in French medical malpractice system is shown in figure 1.

\section{Data source}

The Sou Médical-Groupe MACSF database has gathered information from a nationwide medical insurance company covering approximately 3500 paediatricians and $45000 \mathrm{GPs}$ in France. It corresponds to about $60 \%$ of all physicians working in France. This database has included the claims submitted to regions' government-appointed review board, regardless of their outcomes. For each case, there were two types of claim files: a principal claim file and a secondary claim file. The principal claim file was the repository of information accumulated by the insurer during the life of a claim. It has captured a wide variety of data, including the statement of claim, depositions, interrogatories and other litigation-related documents; reports of internal investigations; expert opinions; medical reports and records detailing the plaintiff's pre-event and post-event condition. The secondary claim file, available since 2003 in electronic format, was a summary of the information contained in the primary file. We were authorised to access any part of the secondary files except those related to outcomes of the malpractice claims, and a limited number of principal files.

\section{Extracted data}

The secondary claim files were reviewed at the insurers' office. For each case, medical investigators (AN, AM) extracted demographic data (age and sex of the patient, activity of the practitioner, date of the claim), the medical condition involved, the alleged misadventure and the outcome of the patient involved in the claim. Medical investigators (AN, AM) then reviewed and classified the data into computerised analysis files.

\section{Definitions}

For reasons of clarity, definitions of some terms are given. Claims: any formal litigation that alleges an error or omission on the part of one or more defendants, and demands for compensation by money or services to claimants.

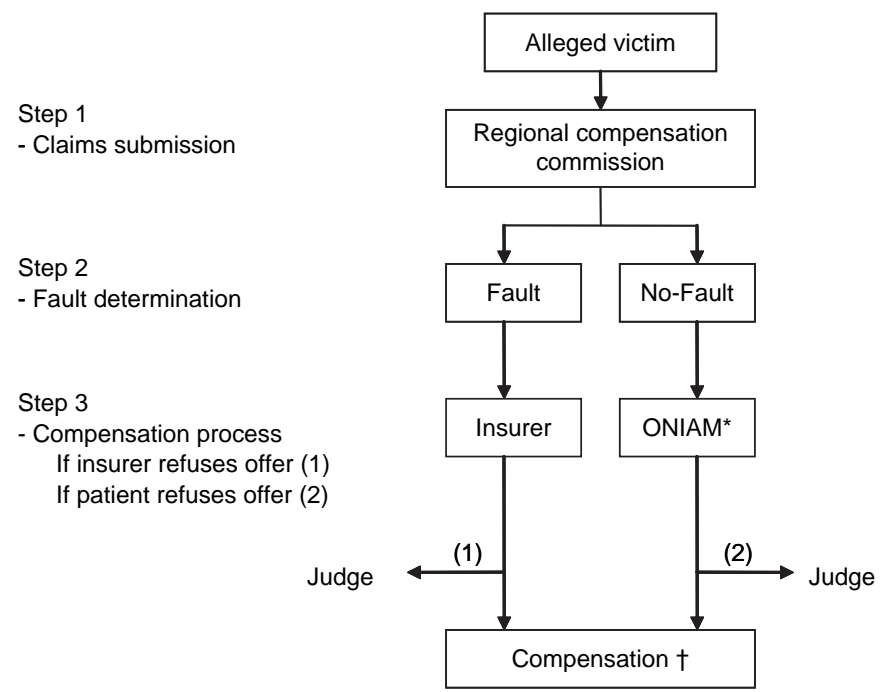

Figure 1 Compensation process in medical malpractice system in France. ${ }^{*}$ ONIAM (Office National d'Indemnisation des Accidents Médicaux) takes responsibility for no-fault payments. IIf injuries have resulted in invalidity $\geq 25 \%$.
Medical error: incorrect medical care, whether action or inaction, that had the potential to cause substantive harm.

Misadventure: the underlying cause of a claim was designated as a 'misadventure'. Ten misadventures (diagnosis errors, treatment errors, no medical errors, etc) were used to classify underlying causes. ${ }^{6}$ No medical errors were those that were believed to have legal merit without associated medical mishap.

Outcome measure: according to the Sou Médical-Groupe MACSF criteria, the severity of a patient's injury was classified into four categories: no injury, minor injury, major injury and death.

\section{Analysis}

First, the general statistics of claims were described and the incidence of medical malpractice claims within this medical insurance was calculated for paediatricians. Second, the characteristics of the patients and the most common diagnoses involved in the claims in general and by age group were described. Third, we determined the most frequent alleged misadventures, and the outcome of the patients involved in the claims. Fourth, the subset of the most common diagnoses was the focus of further analyses. For these cases, we reviewed the primary claim files, and completed an additional form that collected additional clinical information about each case, to determine whether a medical error has occurred during the patient's care. Finally, our results were compared with those from recently published studies analysing paediatric malpractice claims reported to the Physician Insurers Association of America (PIAA). ${ }^{6-8}$

This type of study, which involves no intervention, does not require approval from an ethics committee in France. The database was approved by the Conseil National Informatique et Liberté.

\section{RESULTS}

Two hundred and ninety-eight paediatric malpractice claims involving paediatricians or GPs were extracted. Of these, 70 cases $(23 \%)$ related to the neonatal period were excluded and 228 cases (77\%), involving children between 1 month and 18 years of age, were analysed. Of these 228 cases, 153 cases (67\%) were against GPs (0.07 claim per 100 GPs per year) and 75 cases (33\%) against paediatricians (0.42 claim per 100 paediatricians per year).

Malpractice claims were more frequent in children aged between 1 month and 2 years (41\%) rather than in other age groups: $3-11$ years $(29 \%), 12-18$ years $(30 \%)$. The sex ratio

Table 1 Prevalence and mortality of the top 10 diagnoses involved in 228 paediatric malpractice claims ${ }^{*}$

\begin{tabular}{llll}
\hline & No & $\%^{*}$ & Death (\%) \\
\hline Meningitis & 14 & 7.1 & 93 \\
Dehydration & 13 & 6.6 & 92 \\
Malignancy & 13 & 6.6 & Ndt \\
Pneumonia & 10 & 5.1 & 50 \\
Appendicitis & 10 & 5.1 & 40 \\
Testicular torsion & 9 & 4.6 & 0 \\
Upper limb trauma & 7 & 3.6 & 0 \\
Asthma & 6 & 3.0 & 66 \\
Lower limb trauma & 6 & 3.0 & 0 \\
Otitis & 6 & 3.0 & 0 \\
\hline
\end{tabular}

* There was no medical condition identified in 31 claims. The percentage was calculated among the cases where a medical condition was identified. $\mathrm{tNd}$, not defined. 
was 1.08. Meningitis, dehydration and malignancy were the three most common medical conditions, with the highest death rate (table 1). In 31 cases, there was no medical condition identified: 16 cases were related to adverse events associated with vaccines, and 15 cases related to routine infant or child health check. According to the patient's age, dehydration, meningitis and congenital hip dislocation were the most common diagnoses in malpractice claims involving the youngest children ( 1 month to 2 years of age), pneumonia, malignancy and appendicitis in children from 3 to 11 years of age, and trauma, testicular torsion and malignancy in children from 12 to 18 years of age.

The most common alleged misadventures were diagnosisrelated errors (error or delay) (47\%) and medication errors (13\%) (table 2). When considering the 106 diagnosis-related errors, malignancy was the medical condition most often incorrectly diagnosed (14\%), followed by meningitis (10\%), pneumonia $(9 \%)$, testicular torsion (7\%) and appendicitis (7\%). Detailed analysis of the cases related to meningitis and dehydration identified a medical error in 13 (48\%) of 27 cases during the patient care. Of these errors, $92 \%$ led to death. The most common alleged misadventures were failure to respond appropriately $(31 \%)$, and failure to admit to hospital (31\%) in the cases of dehydration, and diagnosis-related errors (79\%) in those of meningitis. Deaths and major injuries were more frequent in children less than 2 years of age than in older children $52 \%$ vs $35 \%, \mathrm{p}<0.02)$. Of these 228 cases of malpractice claims, 100 cases were closed and 128 ongoing, but data on how the closed cases were settled were not available. These French data are compared with those from the USA in table $3 .{ }^{6-8}$

Table 2 Alleged misadventures in 228 paediatric malpractice claims

\begin{tabular}{lrr}
\hline & No & $\%$ \\
\hline Diagnosis-related error & 106 & 47 \\
Medication error & 30 & 13 \\
No medical error & 22 & 10 \\
Failure to examine & 20 & 9 \\
Failure to respond appropriately & 16 & 7 \\
Treatment related error & 11 & 5 \\
Improper performance of procedure & 10 & 4 \\
Failure to admit to hospital & 7 & 3 \\
Failure to inform patient & 3 & 1 \\
Failure to report child maltreatment & 3 & 1 \\
\hline
\end{tabular}

\section{DISCUSSION}

This study was the first step towards providing a description of paediatric malpractice claims outside the USA. Despite low incidence of malpractice claims in children, the consequence of malpractice is severe in paediatric population especially in children $<2$ years of age, in whom malpractice claims were more frequent than older children, and most often associated with major injuries or deaths.

In our study the average annual incidence of malpractice claims per 100 physicians was 0.42 for paediatricians, and went up to 0.8 when neonatal cases were included. This rate was 0.07 for GPs, and went up to 1.1 when adult cases were included. The average annual incidence of malpractice claims per 100 paediatricians was 6.6 in the USA in $1994,{ }^{9}$ and 0.18 in Japan in 2003. ${ }^{10}$ Paediatricians were ranked 17th among 33 specialties insured by Sou Médical-Groupe MACSF from 2003 to 2007 in terms of number of claims, ${ }^{11}$ and 10 th among 28 specialties insured by PIAA from 1985 to $2005 .^{8}$

Young age was a risk factor for malpractice claims in paediatric care in our study and in North American studies. ${ }^{5}$ In an analysis of 353 randomly selected cases of medical malpractice claims involving children between 0 and 17 years, $77 \%$ were less than 1 year of age. ${ }^{12}$ The incidence of malpractice claims was higher in infants and toddlers; $41 \%$ in our study, and $47 \%$ in children between 0 and 2 years in the USA. ${ }^{6}$ By including in our study the neonatal cases, this rate would have been $55 \%$ in France.

Meningitis was the most common medical condition involved in malpractice claims in our study and the study of Selbst et $a{ }^{6},{ }^{6}$ and the second in the study of Carroll et a $l^{8}$ (table 3 ). This could be explained by the lack of specific signs and sometimes rapid progression of meningitis in infants and young children. Indeed, error or delay in diagnosis of meningitis can markedly increase morbidity and mortality within this age group. Sixty-four per cent of patients with meningitis were less than 2 years of age in our study, and $60 \%$ in the USA. ${ }^{7}$ Dehydration was the first medical condition involved in malpractice claims in children less than 2 years of age, and the second in all children in France (table 3). It is important to note that clinical mismanagement or failure of proper follow-up of infants with severe dehydration could lead to tragic outcomes. Dehydration caused by acute gastroenteritis was the first cause of avoidable death in children in intensive care. ${ }^{13}$

Table 3 Comparison of paediatric malpractice claims in France and in the USA

\begin{tabular}{|c|c|c|c|}
\hline \multirow[b]{2}{*}{ Characteristics } & \multirow[b]{2}{*}{ France } & \multicolumn{2}{|l|}{ USA } \\
\hline & & Carroll et $a l^{8}$ & Selbst et $a I^{6}$ \\
\hline Cases (No) & 228 & 6363 & 2283 \\
\hline Data source & Sou Médical-Groupe MACSF (2003-2007) & PIAA* (1985-2005) & PIAA (1985-2000) \\
\hline Age & 1 month to 18 years & $0-18$ years & $0-18$ years \\
\hline $\begin{array}{l}\text { Physician involved in } \\
\text { claims }\end{array}$ & Paediatrician, GP† & Paediatrician & Physician involved in urgent care \\
\hline $\begin{array}{l}\text { Most common } \\
\text { misadventure }\end{array}$ & Diagnostic error & Diagnostic error & Diagnostic error \\
\hline Most frequent diagnosis & Meningitis & Brain-damaged infant & Meningitis \\
\hline Second diagnosis & Dehydration & Meningitis & Appendicitis \\
\hline Death & $29.5 \%$ & $28.1 \%$ & $\mathrm{Nd} \ddagger$ \\
\hline
\end{tabular}

*PIAA is a trade association of 50 medical malpractice insurance companies insuring $60 \%$ of all private practising physicians and surgeons in the USA.

$\dagger \mathrm{GP}$, general practitioner.

$\ddagger N d$, not defined.

PIAA, Physician Insurers Association of America. 
Diagnostic errors were the most common medical misadventures, notably throughout the last decade in the USA. ${ }^{14-20}$ Diagnosis-related errors accounted for $47 \%$ of alleged misadventures in our study, and $39 \%$ in the USA. ${ }^{6}$ Malignancy and meningitis were the most common diagnoses associated with allegations of diagnostic errors in our study, but meningitis and appendicitis in the PIAA database. ${ }^{7}$

The medical malpractice compensation system in France varies from that in other European countries. While certain countries such as the Scandinavian countries have adopted a no-fault system, others, like the UK, and Germany, have adopted a tort system. These differences, and the absence of publications analysing paediatric medical malpractice claims in other European countries, did not allow us to know to what extent our findings might be similar to those from other European countries. However, the proportion of paid claims may be higher in France than that in countries with tort systems, because injuries not only related to fault, but also certain injuries related to no-fault are compensated.

This study has several limitations. First, while we used malpractice claim files to study medical errors, medical record reviews have been considered the gold standard for this purpose. ${ }^{21-23}$ However, other methods successfully used to study medical errors included direct observation, ${ }^{24} 25$ solicited voluntary reporting of errors, ${ }^{26}$ and malpractice claims review. ${ }^{16}$ Malpractice claim records are an additional resource, including information not always available in medical records. Second, by not having access to all the principal claim files, we were not able to determine the proportion of the claims judged to involve errors. Third, because the litigation outcomes were not available, we did not know how the closed claims were resolved. As such, it was impossible to determine the costs of the claims, and the proportion of the claims that resulted in compensation for the plaintiff. Fourth, our study was restricted to claims registered in only one insurance company's database, but this company covered approximately $60 \%$ of all physicians. Finally, the use of malpractice claims may be a source of bias for addressing patient safety, because severe injuries and younger patients are probably over-represented in the subset of medical injuries that proceed to litigation. ${ }^{27}$

\section{CONCLUSIONS}

Paediatric malpractice claims are less frequent in France than in the USA, but they share many similarities with those in the USA. These malpractice claims involve mainly infants and small children and concentrate on some disorders: meningitis, dehydration, malignancy, pneumonia, appendicitis and trauma, with more serious consequences in small children to whom they result most often in death or major injury. The most frequent misadventure is diagnostic error. These data (ie, malpractice risk information) could increase physicians' awareness of disorders and age groups at high risk of malpractice claims in paediatric care.

Competing interests None.
Provenance and peer review Not commissioned; externally peer reviewed.

\section{REFERENCES}

1. Altman DE, Clancy C, Blendon RJ. Improving patient safety - five years after the IOM report. N Engl J Med 2004;351:2041-3.

2. Department of Health. An Organisation with a Memory: Report of an Expert Group on Learning from Adverse Events in the NHS. London: Stationery Office, 2000. http://www.rcgp.org.uk/pdf/ISS_SUMM00_04.pdf (Accessed 25 March 2010)

3. Kohn LT, Corrigan JM, Donaldson MS., eds. To err is human: building a safer health system. Committee on Quality of Health Care in America, Institute of Medicine, Washington, DC: National Academies Press, 2000.

4. Abenhaim L. latrogénie. In: Analyse des connaissances disponibles sur des problèmes de santé sélectionnés, leurs déterminants, et les stratégies de santé publique. Rapport: Direction Générale de la Santé, 2003:141-52. http://www. sante.gouv.fr/htm/dossiers/losp/rapport integral.pdf (accessed 16 July 2010).

5. Najaf-Zadeh A, Dubos F, Aurel M, et al. Epidemiology of malpractice lawsuits in paediatrics. Acta Paediatr 2008;97:1486-91.

6. Selbst SM, Friedman MJ, Singh SB. Epidemiology and etiology of malpractice lawsuits involving children in US emergency departments and urgent care centers. Pediatr Emerg Care 2005;21:165-9.

7. McAbee GN, Donn SM, Mendelson RA, et al. Medical diagnoses commonly associated with pediatric malpractice lawsuits in the United States. Pediatrics 2008;122:e1282-6.

8. Carroll AE, Buddenbaum JL. Malpractice claims involving pediatricians: epidemiology and etiology. Pediatrics 2007;120:10-7.

9. AAP Committee on Medical Liability. Pediatricians and the law: malpractice claim review offers mixed news for pediatricians. AAP News 2001;18:154.

10. Ehara A. Lawsuits associated with medical malpractice in Japan: rate of lawsuits was very low in pediatrics, although many children visit emergency rooms Pediatrics 2005; 115:1792-3

11. Najaf-Zadeh A, Dubos F, Aurel M, et al. [Incidence of malpractice claims involving pediatricians]. Arch Pediatr 2010;17:183-4.

12. Studdert DM, Mello MM, Gawande AA, et al. Claims, errors, and compensation payments in medical malpractice litigation. N Eng/ J Med 2006;354:2024-33.

13. Martinot A, Lejeune C, Hue V, et al. [Modality and causes of 259 deaths in a pediatric intensive care unit]. Arch Pediatr 1995;2:735-41.

14. Kain ZN, Caldwell-Andrews AA. What pediatricians should know about childrelated malpractice payments in the United States. Pediatrics 2006;118:464-8.

15. Phillips RL, Jr, Bartholomew LA, Dovey SM, et al. Learning from malpractice claims about negligent, adverse events in primary care in the United States. Qual Saf Health Care 2004;13:121-6.

16. Sandars J, Esmail A. The frequency and nature of medical error in primary care: understanding the diversity across studies. Fam Pract 2003;20:231-6.

17. Reynolds SL, Jaffe D, Glynn W. Professional liability in a pediatric emergency department. Pediatrics 1991;87:134-7.

18. Karcz A, Holbrook J, Auerbach BS, et al. Preventability of malpractice claims in emergency medicine: a closed claims study. Ann Emerg Med 1990;19:865-73.

19. Ricci JA, Lambert RL, Steffes DG. Pediatrics and professional liability. Pediatr Emerg Care 1986;2:106-8.

20. Trautlein JJ, Lambert RL, Miller J. Malpractice in the emergency department review of 200 cases. Ann Emerg Med 1984;13:709-11.

21. Wilson RM, Runciman WB, Gibberd RW, et al. The Quality in Australian Health Care Study. Med J Aust 1995;163:458-71.

22. Brennan TA, Leape LL, Laird NM, et al. Incidence of adverse events and negligence in hospitalized patients. Results of the Harvard Medical Practice Study I. N Engl J Med 1991;324:370-6.

23. Woods D, Thomas E, Holl J, et al. Adverse events and preventable adverse events in children. Pediatrics 2005;115:155-60.

24. Andrews LB, Stocking C, Krizek T, et al. An alternative strategy for studying adverse events in medical care. Lancet 1997;349:309-13.

25. Proctor ML, Pastore J, Gerstle JT, et al. Incidence of medical error and adverse outcomes on a pediatric general surgery service. J Pediatr Surg 2003;38:1361-5.

26. Fordyce J, Blank FS, Pekow P, et al. Errors in a busy emergency department. Ann Emerg Med 2003;42:324-33.

27. Studdert DM, Thomas EJ, Burstin HR, et al. Negligent care and malpractice claiming behavior in Utah and Colorado. Med Care 2000;38:250-60. 